\title{
Hemato-Biochemical Studies of Hepatobiliary Disorders in Dogs
}

\author{
K. Lakshmi ${ }^{\text {* }}$, K. Padmaja ${ }^{2}$, P. Nagaraj ${ }^{2}$, A. Gopala Reddy ${ }^{3}$ and M. Gnana Prakash ${ }^{4}$ \\ ${ }^{1}$ Department of Veterinary Medicine, College of Veterinary Science, Rajendranagar, \\ Hyderabad-500030, Telangana state, India \\ ${ }^{2}$ Veterinary Clinical Complex, Bhoiguda, Hyderabad-500030, Telangana state, India \\ ${ }^{3}$ Department of Pharmacology, Hyderabad-500030, Telangana state, India \\ ${ }^{4}$ Department of Animal Genetics and Breeding, Hyderabad-500030, Telangana state, India
}

*Corresponding author

\section{A B S T R A C T}

\section{Keywords}

Hepatobiliary disorders, Dogs,

Hematology, Serum biochemistry

Article Info

Accepted:

12 December 2017

Available Online:

10 January 2018
A total of 140 dogs were diagnosed with hepatobiliary disorders based on clinico, hemato-biochemical and diagnostic imaging. Out of which, 32 dogs were diagnosed with diffuse parenchymal disorders with ascites, 32 dogs with diffuse parenchymal disorders without ascites, 24 with focal parenchymal disorders and 52 with biliary tract disorders. Significantly decreased hemoglobin and total erythrocyte count with elevated total leucocyte count and neutrophil count were common hematological abnormalities. Similarly, elevated activity of ALT, AST, ALP, GGT, total bilirubin, direct bilirubin and globulin with decreased levels of total protein, albumin, glucose and serum electrolytes (sodium, potassium and chloride) were common biochemical findings recorded in all hepatobiliary disorders affected dogs.

\section{Introduction}

Hepatobiliary dysfunctions occur in a number of acute and chronic clinical conditions. Druginduced hepatotoxicity, infectious diseases, congenital or neoplastic diseases, metabolic disorders, degenerative processes, vascular injury, auto-immune diseases and even blunt trauma may result in hepatobiliary dysfunctions according to Kumar et al., (2013). The WSAVA (World Small Animal Veterinary Association) liver standardization group recently categorized hepatic disorders in dogs into four main types viz., parenchymal, biliary tract, vascular and neoplastic liver disorders (Geschen, 2009). As the liver is physiologically and anatomically diverse, there is no single test that adequately identifies hepatic disease or its underlying cause. For this reason, a battery of tests must be used to diagnose the hepatobiliary affections. A reasonable package of screening tests recommended for an animal suspected of having hepatobiliary disease includes a complete blood count (CBC), serum biochemical profile, urinalysis, faecal 
analysis, survey radiography and Ultrasonography (Kumar et al., 2013).

\section{Materials and Methods}

Dogs presented to Veterinary Hospital, Bhoiguda with the clinical signs of anorexia, ascites, jaundice, pale mucous membranes, vomition, lethargy, polyuria and polydipsia and other manifestations suggestive of hepatobiliary disorders were selected. While, apparently healthy dogs presented for general health checkup and vaccination with no clinical condition in the age group of 2-5 years irrespective of breed and sex were selected randomly as healthy control group for this study. However, dogs with hepatobiliary disorders due to infectious origin were excluded from the study.

Blood was collected from the peripheral (cephalic/saphenous) veins of dogs suffering with hepatobiliary disorders in dogs using sterile vaccutainers containing EDTA (ethylene di amine tetra acetic acid- $2 \mathrm{mg} / \mathrm{ml}$ blood) and sodium fluoride as anticoagulants for estimation of hematological parameters and blood glucose, respectively.

Hematological parameters were estimated as described by Schalm et al., (1986). Blood was also collected into sterile clean vaccutainers containing clot activator for serum separation and was centrifuged at 3000rpm for 15 minutes and the serum collected was transferred into Eppendorf tubes and stored at $-20^{\circ} \mathrm{C}$ for estimation of biochemical parameters.

Serum samples were analyzed using star21 plus semi-automatic biochemical analyzer and commercially available diagnostic kits supplied by M/S Rapid diagnostics Pvt. Ltd., New Delhi. Further, blood and serum was collected from apparently healthy dogs to obtain normal values.

\section{Results and Discussion}

Hematological examination of the affected dogs revealed a significant $(\mathrm{P}<0.01)$ decrease in the hemoglobin values in all the groups of hepatobiliary disorders as compared with healthy control dogs. The reduction in the mean values of hemoglobin was attributed to the increased degradation of red blood cells and the possible causes of which may be the increased transit time of erythrocytes through the spleen due to reduced portal blood flow or increased fragility of red blood cells due to high levels of bile acids (Rothuizen and Meyer, 2000). There was a significant $(\mathrm{P}<0.01)$ decrease in the mean total erythrocyte count levels in diffuse parenchymal disorders with ascites, without ascites and biliary tract disorders. While, there was a significant decrease $(\mathrm{P}<0.05)$ in focal parenchymal disorders. Similar findings of reduced TEC in dogs affected with ascites of hepatic origin and hepatobiliary disorders were reported earlier by Chaturvedi et al., (2013) and Bhadesiya et al., (2015). The reduction in the mean values of TEC might be due to the increased degradation of $\mathrm{RBC}$ (Rothuizen and Meyer, 2000). However, a significant $(\mathrm{P}<0.01)$ increase in the mean values of total leucocyte count was noticed in diffuse parenchymal disorders with ascites along with a significant $(\mathrm{P}<0.05)$ increase among diffuse parenchymal disorders without ascites and biliary tract disorders. While, a non- significant increase was observed among focal parenchymal disorders as compared with healthy control dogs. Similar findings of leucocytosis were reported by Tantary et al., (2014) in a dog affected with hepatic disorders. There was a significant $(\mathrm{P}<0.05)$ decrease in the mean values of packed cell volume in focal parenchymal disorders and a non-significant decrease was noticed in diffuse parenchymal disorders with ascites, without ascites and biliary tract disorders. The reduction in the mean values of $\mathrm{PCV}$ in the 
present study might be due to the dehydration seen in the dogs affected with various hepatobiliary disorders. Increased neutrophils were significant in biliary tract disorders $(\mathrm{P}<0.01)$, while in diffuse parenchymal disorders with ascites, without ascites and focal parenchymal disorders it was $\mathrm{P}<0.05$. No significant change was noticed with respect to lymphocytes, monocytes, eosinophils and basophils in all dogs with hepatobiliary disorders as compared with healthy control (Table 1). Neutrophilic leucocytosis was a characteristic feature of ongoing acute inflammatory conditions as reported by Poldervaart et al., (2009)

Biochemical profile revealed a significant $(\mathrm{P}<0.01)$ increase in the mean alanine amino transferase (ALT) activity in diffuse parenchymal disorders with ascites and $(\mathrm{P}<0.05)$ in diffuse parenchymal disorders without ascites, focal parenchymal disorders and biliary tract disorders as compared with healthy control. There was a significant $(\mathrm{P}<0.01)$ increase of AST levels in all the dogs of hepatobiliary disorders. Serum concentrations of ALT and AST are the most commonly measured markers of hepatocellular leakage in dogs (Lidburg and Steiner, 2013). ALT and AST are indicative of altered hepato cellular membrane permeability, hepatocellular necrosis and inflammation with degree proportional to number of injured hepatocytes (Kramer and Hoffman, 1997).

A significant $(\mathrm{P}<0.01)$ increase in ALP was noticed in diffuse parenchymal disorders with ascites and biliary tract disorders, and a significant increase $(\mathrm{P}<0.05)$ among the dogs affected with diffuse parenchymal disorders without ascites and focal parenchymal disorders. The mean gamma glutamyl transferase (GGT) values were significantly $(\mathrm{P}<0.01)$ elevated in biliary tract disorders and $(\mathrm{P}<0.05)$ in diffuse parenchymal disorders with ascites, without ascites and focal parenchymal disorders.). Elevation in the serum ALP levels along with GGT was seen with the administration of drugs like corticosteroids. (Meyer, 2013) and was the most common among cholestatic disorders. Therefore, they were considered as cholestatic markers, which are synthesized in response to the retained bile (Webster, 2010).

The mean total bilirubin and direct bilirubin levels were significantly $(\mathrm{P}<0.05)$ elevated in biliary tract disorders, while a non-significant increase was reported in diffuse parenchymal disorders with ascites, without ascites and focal parenchymal disorders. Total bilirubin concentrations indicate the hepatic ability for uptake, conjugation and excretion of the bilirubin (Sevelius and Jonsson, 1995).

The mean total protein values were significantly decreased in diffuse parenchymal disorders with ascites $(\mathrm{P}<0.01)$ and $(\mathrm{P}<0.05)$ in diffuse parenchymal disorders without ascites, focal parenchymal disorders and biliary tract disorders as compared with healthy control. The mean albumin levels were significantly $(\mathrm{P}<0.01)$ lower in diffuse parenchymal disorders with ascites and a significant decrease $(\mathrm{P}<0.05)$ in diffuse parenchymal disorders without ascites and biliary tract disorders. The reduction was nonsignificant in focal parenchymal disorders. A significantly $(\mathrm{P}<0.01)$ elevated levels of mean globulin were recorded among focal parenchymal disorders and biliary tract disorders and a significant $(\mathrm{P}<0.05)$ increase in diffuse parenchymal disorders with ascites and without ascites was seen. These findings of the present investigation corroborated well with the findings of James and Pillai (2011), who observed hypoprotenemia in dogs affected with hepatic cirrhosis. Most of the plasma proteins were synthesized and catabolised by the liver and form a vulnerable indicator of compromised hepatic function. 
Table.1 Mean hematological findings in healthy and hepatobiliary disorders in dogs

\begin{tabular}{|c|c|c|c|c|c|c|}
\hline S.No & Parameter & $\begin{array}{l}\text { Healthy } \\
\text { control }\end{array}$ & $\begin{array}{l}\text { Diffuse parenchymal } \\
\text { disorders with ascites }\end{array}$ & $\begin{array}{l}\text { Diffuse parenchymal } \\
\text { disorders without ascites }\end{array}$ & $\begin{array}{c}\text { Focal parenchymal } \\
\text { disorders }\end{array}$ & $\begin{array}{c}\text { Biliary } \\
\text { Tract disorders }\end{array}$ \\
\hline 1 & Hb (g/dl) & $12.92 \pm 0.44$ & $9.06 \pm 0.24^{* *}$ & $9.01 \pm 0.24^{* *}$ & $10.26 \pm 0.28^{* *}$ & $9.73 \pm 0.19^{* *}$ \\
\hline 2 & TEC (X 10 $\% / \mu L)$ & $7.19 \pm 0.23$ & $4.64 \pm 0.13^{* *}$ & $3.69 \pm 0.13^{\text {** }}$ & $5.37 \pm 0.15^{*}$ & $4.51 \pm 0.99^{* *}$ \\
\hline 3 & $\operatorname{TLC}\left(X 10^{3} / \mu \mathrm{L}\right)$ & $8.66 \pm 1.65$ & $23.73 \pm 0.92^{* *}$ & $20.29 \pm 0.92^{*}$ & $10.71 \pm 1.06$ & $17.33 \pm 0.72^{*}$ \\
\hline 4 & PCV (\%) & $41.73 \pm 1.34$ & $38.81 \pm 3.69$ & $40.34 \pm 3.91$ & $34.54 \pm 0.73^{*}$ & $36.48 \pm 2.47$ \\
\hline 5 & Neutrophils (\%) & $58.98 \pm 2.70$ & $80.04 \pm 1.51^{*}$ & $80.76 \pm 1.51^{*}$ & $67.97 \pm 1.75^{*}$ & $83.92 \pm 1.19^{* *}$ \\
\hline 6 & Lymphocytes (\%) & $31.90 \pm 0.75$ & $26.61 \pm 4.07$ & $29.25 \pm 4.02$ & $30.69 \pm 3.67$ & $31.09 \pm 0.68$ \\
\hline 7 & Monocytes (\%) & $2.18 \pm 0.29$ & $2.45 \pm 0.88$ & $3.41 \pm 0.96$ & $2.08 \pm 0.12$ & $2.19 \pm 0.07$ \\
\hline 8 & Eosinophils (\%) & $2.50 \pm 0.18$ & $1.97 \pm 0.10$ & $2.55 \pm 0.10$ & $1.62 \pm 0.12$ & $2.29 \pm 0.79$ \\
\hline 9 & Basophils (\%) & $0.48 \pm 0.24$ & $0.52 \pm 0.12$ & $0.49 \pm 0.41$ & $0.45 \pm 0.14$ & $0.44 \pm 0.23$ \\
\hline
\end{tabular}

* Significant at $(\mathrm{P}<0.05),{ }^{* *}$ Significant at $(\mathrm{P}<0.01)$

Table. 2 Mean biochemical findings in healthy and hepatobiliary disorders in dogs

\begin{tabular}{|c|c|c|c|c|c|c|}
\hline S.No & Parameter & $\begin{array}{l}\text { Healthy } \\
\text { control }\end{array}$ & $\begin{array}{l}\text { Diffuse parenchymal } \\
\text { disorders with ascites }\end{array}$ & $\begin{array}{l}\text { Diffuse parenchymal } \\
\text { disorders without ascites }\end{array}$ & $\begin{array}{c}\text { Focal parenchymal } \\
\text { disorders }\end{array}$ & $\begin{array}{c}\text { Biliary } \\
\text { Tract disorders }\end{array}$ \\
\hline 1. & $\mathbf{A L T}(\mathbf{U} / \mathbf{L})$ & $32.80 \pm 1.60$ & $203.19 \pm 19.16^{* *}$ & $197.58 \pm 34.72^{*}$ & $109.76 \pm 6.79^{*}$ & $88.23 \pm 10.66^{*}$ \\
\hline 2. & $\operatorname{AST}(\mathbf{U} / \mathbf{L})$ & $43.05 \pm 1.22$ & $184.84 \pm 22.32^{* *}$ & $154.18 \pm 19.61^{* *}$ & $141.10 \pm 10.31^{* *}$ & $71.23 \pm 3.76^{* *}$ \\
\hline 3. & $\mathbf{A L P}(\mathbf{U} / \mathbf{L})$ & $59.62 \pm 2.08$ & $284.82 \pm 18.39^{* *}$ & $251.98 \pm 20.73^{*}$ & $85.72 \pm 2.84^{*}$ & $435.51 \pm 34.23^{* *}$ \\
\hline 4. & GGT(U/L) & $3.04 \pm 0.15$ & $6.64 \pm 0.51^{*}$ & $6.70 \pm 0.57^{*}$ & $4.74 \pm 0.18^{*}$ & $14.04 \pm 0.68^{* *}$ \\
\hline 5. & TB(m g/dl) & $0.45 \pm 0.03$ & $1.17 \pm 0.04$ & $1.07 \pm 0.05$ & $0.93 \pm 0.06$ & $3.85 \pm 0.52^{*}$ \\
\hline 6. & $\mathrm{DB}(\mathrm{mg} / \mathrm{dl})$ & $0.19 \pm 0.02$ & $0.75 \pm 0.05$ & $0.67 \pm 0.03$ & $0.38 \pm 0.03$ & $1.06 \pm 0.31^{*}$ \\
\hline 7. & Total Protein (g/dl) & $6.22 \pm 0.03$ & $4.77 \pm 0.10^{* *}$ & $5.45 \pm 0.09^{*}$ & $5.32 \pm 0.12^{*}$ & $5.28 \pm 0.09^{*}$ \\
\hline 8. & $\operatorname{Albumin}(\mathrm{g} / \mathrm{dl})$ & $2.81 \pm 0.07$ & $2.01 \pm 0.03^{* *}$ & $2.34 \pm 0.09^{*}$ & $2.68 \pm 0.09$ & $2.35 \pm 0.07^{*}$ \\
\hline 9. & Globulins(g/dl) & $3.41 \pm 0.07$ & $3.43 \pm 0.01^{*}$ & $3.44 \pm 0.09^{*}$ & $3.65 \pm 0.14^{* *}$ & $3.96 \pm 0.09^{* *}$ \\
\hline 10. & Glucose (mg/dl) & $108.24 \pm 1.87$ & $90.86 \pm 1.39^{* *}$ & $100.76 \pm 0.21^{* *}$ & $104.80 \pm 1.20^{* *}$ & $81.14 \pm 2.32^{* *}$ \\
\hline 11. & Cholesterol(mg/dl) & $166.89 \pm 2.28$ & $118.72 \pm 17.25$ & $151.23 \pm 33.65$ & $111.34 \pm 4.14$ & $343.39 \pm 27.11^{*}$ \\
\hline 12. & CKMb (U/L) & $25.29 \pm 0.61$ & $24.95 \pm 0.46$ & $25.03 \pm 0.72$ & $25.21 \pm 0.81$ & $26.02 \pm 0.57$ \\
\hline 13. & BUN (mg/dl) & $15.26 \pm 0.09$ & $20.08 \pm 0.69$ & $19.54 \pm 0.73$ & $18.05 \pm 0.43$ & $15.49 \pm 0.26$ \\
\hline 14. & Creatinine (mg/dl) & $1.08 \pm 0.07$ & $1.21 \pm 3.03$ & $1.16 \pm 0.03$ & $0.95 \pm 0.05$ & $0.99 \pm 0.03$ \\
\hline 15. & Sodium (mEq/L) & $142.16 \pm 0.38$ & $134.77 \pm 1.23$ & $138.13 \pm 1.37$ & $137.91 \pm 1.18$ & $136.86 \pm 0.49$ \\
\hline 16. & Potassium $(\mathrm{mEq} / \mathrm{L})$ & $4.05 \pm 0.35$ & $3.56 \pm 0.08$ & $3.60 \pm 0.08$ & $3.69 \pm 0.09$ & $4.01 \pm 0.04$ \\
\hline 17. & Chloride (mEq/L) & $103.12 \pm 0.35$ & $97.87 \pm 0.85$ & $96.13 \pm 1.23$ & $100.63 \pm 3.01$ & $102.18 \pm 0.41$ \\
\hline
\end{tabular}

Significant at $(\mathrm{P}<0.05),{ }^{* *}$ Significant at $(\mathrm{P}<0.01)$ 
The mean glucose values were significantly $(\mathrm{P}<0.01)$ decreased in all the groups of hepatobiliary disorders when compared with healthy control. Hypoglycemia was a very specific sign of marked reduction in liver function and in cases of end stage chronic liver failure (Webster, 2010).

The mean cholesterol levels were significantly $(\mathrm{P}<0.05)$ elevated in biliary tract disorders and a non-significant reduction in diffuse parenchymal disorders with ascites, without ascites and focal parenchymal disorders.

These findings corroborate with findings of Tantary et al., (2014), who recorded reduced cholesterol levels in dogs affected with hepatic disorders. While hyper cholesteremia was reported by Maddison (2016) in dogs diagnosed with partial or complete biliary obstruction.

Hypocholesteremia may be due to long lasting liver disease as a result of the drop in the production or absorption from the intestines or higher conversion to bile acids (Webster, 2010).

No significant change was noticed with respect to mean creatine kinase $\mathrm{MB}(\mathrm{CK}-\mathrm{Mb})$ values when compared with healthy control dogs. These findings are in agreement with Schober (2005), who reported that CK-Mb was more specific to cardiac muscle and alteration in these levels were noticed among cardiac diseases.

No significant difference in the values was recorded in BUN and creatinine levels with diffuse parenchymal disorders with ascites and within normal limits among diffuse parenchymal disorders without ascites, focal parenchymal disorders and biliary tract disorders as compared with healthy control dogs. These findings are in agreement with
Elhiblu et al., (2015), who stated that renal dysfunction was a frequent complication in patients with end stage disease and hence increased BUN and creatinine values could be attributed to impaired kidney function associated with liver cirrhosis due to decreased capacity of the liver to detoxify the harmful products.

There was a non-significant decrease in sodium, potassium and chloride levels among diffuse parenchymal disorders with ascites, without ascites, focal parenchymal disorders and biliary tract disorders when compared with healthy control (Table 2).

These findings are in agreement with Ram Prabhu et al., (2002), who stated that chronic vomiting will typically cause decreased serum electrolytes in dogs owing to their loss in the vomitus.

\section{References}

Bhadesiya, C. M., Jani, R. G., Parikh, P. V., Pandey, A. M., Neha Rao and Shai, A. 2015. Haemato-biochemistry and imaging study on ascites with hepatic and cardiac involvement in a German Shepherd pup.

International Research Journal of Chemistry.(11):14-22.

Chaturvedi, M., Gonaie, A. H., Shekawat, M. S., Chaudhary, D., Jatkhar, A. and Chaudhari, M. 2013. Serum hemato-biochemical profile in ascitic dogs. Haryana Veterinary Journal, 52: 129-130.

Elhiblu, M. A., Dua, K., Mohindroo, J., Mahajan, S. K., Sood, N. K., Dhaliwal, P. S. 2015. Clinico- haemato biochemical profile of dogs with liver cirrhosis. Veterinary World 8(4): 487-491.

Geschen, L. 2009. Update on hepatobiliary imaging. Small Animal Practice, 39: 439467.

James, A. A. and Pillai, U. N. 2011. Ultrasonogrpahic diagnosis of cirrhosis in a dog. Journal of Veterinary Animal Science, (42): 64-65.

Kramer, J. W. and Hoffman W. E. 1997. Clinical 
enzymology.In: clinical biochemistry of domestic animals. Kaneko J J Harvey and M Bruss, (eds) Academic Press London: 330.

Kumar, M., Mondal, D. B., Saravanan, M. and Sharma, K. 2013. Therapeutic management of hepato biliary dysfunction in canines, Intas polivet. 14(1): 117-120.

Lidburg, A. J. and Steiner, J. M. 2013. Diagnostic evaluation. Chapter.61. Liver, In Washabau $\mathrm{R} \mathrm{J}$ and Day M J. Text book of canine and feline gasteroenterology. Elsevier publishers. PP. 863-879.

Lucena, R., Mozos, E., Bautista, M. J., Ginel, P. J. and Perez, J. 2001. Hepatic cirrhosis in five month old dog. Journal of Small Animal Practice. 42: 239-242.

Maddison, J.E 2016. Diagnosis of hepatobiliary disease in dogs and cats- What do the tests really mean? Proceedings of $15^{\text {th }}$ World Small Animal Veterinary Association (WSAVA), $8^{\text {th }}$ federation of Small animal Practitioners Associations of India (FSAPA) Continuing education programme on companion animal practice. November $11^{\text {th }}-13^{\text {th }} 2016$ Chandigarh, India: Pp. 1-44.

Meyer, H. P. and Rothuizen, J. 2013. Liver.Chapter.61 Liver In: Washabau R J and Day M J. Text book of canine and feline gasteroenterology. Elsevier publishers. Pp. 849-972.

Poldervaart, J. H., Favier, R. P., Penning, L.C., Van den Ingh, T. S. G.A. M. and Rothuizen, J. 2009. Primary hepatitis in dogs: A retrospective review (2002 -2006). Journal of Veterinary Internal Medicine, 23: 72-80.

Ramprabhu, R., Prathaban, S., Nambi, A. P. and
Dhanpalan, P. 2002. Hemorrhagic gastro enteritis in dogs. A clinical Profile. Indian Veterinary Journal, 79: 374-376.

Rothuizen, J. and Meyer, H.P 2000. History, physical examination and signs of liver diseases. In: Ettinger S J and Feldman E C. Text book of Veterinary Internal Medicine. $5^{\text {th }}$ edn., W B Saunders Co., Philadelphia. Pp. 1272-1277.

Schalm, O.W., Jain, N. C. and Carol, E. J., 1986. Text book of Veterinary Hematology, 4th edition, Lea and Febiger, Philadelphia: 1529.

Schober, K. E. 2005. Biochemical markers of cardiovascular disease. Chapter 198.In: Text book of Veterinary Internal Medicine, Diseases of the dog and cat. $6^{\text {th }}$ edition, vol.III, edt by: Stephen J. Ettinger and Edward C. Feldman, Elsevier publishers. Pp. 94-948.

Sevelius, E. and Jonsson, L. 1995. Liver disease. Chapter 9.Manual of canine and feline Gastro enterolgy. Edited by David Thomas, James W Simpson and Ed. J. Hall. BSAVA Publishers U.K. Pp. 191220.

Tantary, H. A., Soodan, J. S., Chirag, S., Ansari, M. M., Kumar, S. and Imtiyaz, T. 2014. Diagnostic studies in dogs with hepatic disorders. International Journal of Veterinary Science, 3(4): 210-215.

Webster, C. R. L. 2010. History, clinical signs and physical findings in hepatobiliary disease. In Text book of Veterinary internal Medicine, Ettinger $\mathrm{S} \mathrm{J}$ and Feldman $\mathrm{E}$ (eds) $7^{\text {th }}$ edition, St.Louis, ElsevierSaunders, pp. 1612-1618.

\section{How to cite this article:}

Lakshmi, K., K. Padmaja, P. Nagaraj, A. Gopala Reddy and Gnana Prakash, M. 2018. HematoBiochemical Studies of Hepatobiliary Disorders in Dogs. Int.J.Curr.Microbiol.App.Sci. 7(01): 1406-1411. doi: https://doi.org/10.20546/ijcmas.2018.701.172 